\title{
Fatores que Impactam a Divulgação Voluntária de Informações Socioambientais na Percepção dos Gestores ${ }^{1}$
}

\section{Factors Impacting the Voluntary Disclosure of Information on Social and Environmental Perception Managers}

\section{Factores que Afectan la Difusión de Información Ambiental Voluntaria en la Percepción de los Administradores}

\author{
Nayara Batista Moreira, MSc. \\ Programa de Pós-graduação em Ciências Contábeis \\ Universidade Federal da Bahia \\ Endereço: Praça da Peidade, nº 6, Centro, CEP: \\ 40.060.160, Salvador, BA, Brasil. \\ Telefone: (71) 8742-6500 / (71) 3283-7569 \\ e-mail: mgc.ba@hotmail.com \\ Sônia Maria da Silva Gomes, Dr ${ }^{\mathrm{a}}$ \\ Professora do Programa de Pós-graduação em \\ Ciências Contábeis - UFBA \\ Endereço: Praça da Peidade, no 6, Centro, CEP: \\ 40.060.160, Salvador, BA, Brasil. \\ Telefone: (71) 8893-3428 / (71) 3283-7569 \\ e-mail: songomes@ufba.br
}

\author{
José Maria Dias Filho, Dr. \\ Professor do Programa de Pós-Graduação em Ciências \\ Contábeis, Universidade Federal da Bahia, Faculdade \\ de Ciências Contábeis. \\ Endereço: Praça 13 de maio, no 06, Piedade, CEP: \\ 40.070-010 - Salvador, BA - Brasil \\ Telefone: (71) 3283-7569 \\ e-mail: zemariadias@uol.com.br \\ Mirian Gomes Conceição, MSc. \\ Programa de Pós-graduação em Ciências Contábeis - \\ UFBA, Professora da Faculdade Anísio Teixeira (FAT) \\ Endereço: Praça da Peidade, no 6, Centro, CEP: \\ 40.060.160, Salvador, BA, Brasil. \\ Telefone: (71) 8738-3946 / (71) 3283-7569 \\ e-mail: $\underline{\text { mgc.ba@hotmail.com }}$
}

\section{RESUMO}

O presente estudo buscou identificar, com base na Teoria da Legitimidade, quais fatores impactam a divulgação voluntária de informações socioambientais, na percepção dos gestores. Para alcançar tal objetivo, desenvolveu-se uma pesquisa descritiva cuja amostra é composta por gestores de cinco das dez maiores companhias do setor de energia elétrica que operam no Brasil, segundo a Revista Exame 2010. Os dados foram coletados através de questionário e analisados estatisticamente por meio do teste não paramétrico de Kruskall-Wallis, que tem por finalidade comparar a média das respostas coletadas. Os resultados indicam que os principais fatores que impactam a decisão dos gestores em evidenciar informações socioambientais são as preocupações com a imagem e a reputação da empresa, a valorização das ações, a oportunidade de novas fontes de financiamento e a competitividade empresarial. Assim, este estudo procurou contribuir para ampliar e fortalecer o debate acerca do

\footnotetext{
${ }^{1}$ Artigo recebido em 19.11.2013. Revisado pelos pares em 29.01.2014 (blind review). Ajustado e Aceito para publicação em 01.03.2014. Recomendado para publicação por José Ribamar Marques de Carvalho (Editor Científico). Publicado em 10.04.2014. Organização responsável UACC/CCJS/UFCG.
} 
poder explicativo da teoria da legitimidade, notadamente no que diz respeito aos fatores que influenciam a divulgação voluntária de informações socioambientais.

Palavras-chave: Evidenciação socioambiental; Teoria da legitimidade; Percepção dos gestores.

\begin{abstract}
The present study sought to identify, based on the Legitimacy Theory, which factors impact on the voluntary disclosure of social and environmental information in the perception of managers. In an attempt to achieve this goal, we developed a descriptive study, whose sample is composed of managers of five of the ten largest companies in the electricity sector of Brazil according to EXAME Magazine 2010. Data were collected through questionnaire and analyzed statistically using the nonparametric test of Kruskal-Wallis, whose purpose is to compare the average of the responses collected. The results showed that the main factors that impact the decision makers in the disclosure of social and environmental information are concerns about the image and reputation of the company, stock appreciation, opportunity for new finance sources and business competitiveness. Thus, this study sought to contribute to the discussion of the application of the legitimacy theory to explain the aspects related to voluntary disclosure of social and environmental information.
\end{abstract}

Keywords: Social and Environmental Disclosure. Legitimacy Theory. Managers Perception.

\title{
RESUMEN
}

El presente estudio trató de identificar, con base en la Teoría de la legitimidad, que los factores de impacto de la divulgación voluntaria de información ambiental en la percepción de los directivos. Para lograr este objetivo, se desarrolló un estudio descriptivo cuya muestra está compuesta por directivos de cinco de las diez mayores empresas del sector eléctrico que operan en Brasil, de acuerdo con la Revista Exame 2010. Los datos fueron recolectados a través de un cuestionario y analizados estadísticamente mediante el test de Kruskal -Wallis no paramétrico, que tiene como objetivo comparar la media de las respuestas recogidas. Los resultados indican que los principales factores que los tomadores de decisiones de impacto en el medio ambiente están poniendo de relieve las preocupaciones sobre la imagen y reputación de la empresa, la valoración de las acciones, la posibilidad de nuevas fuentes de financiación y la competitividad empresarial. Así, este estudio trata de contribuir a la expansión y fortalecimiento del debate sobre el poder explicativo de la teoría de la legitimidad, especialmente con respecto a los factores que influyen en la revelación voluntaria de información ambiental.

Palabras clave: Divulgación ambiental. Teoría de la legitimidade. Percepción de los gerentes.

\section{INTRODUÇÃO}

De acordo com Campbell (2007), é importante reconhecer que o terreno institucional em que operam as corporações não é estático. Neste ambiente, há pressões dinâmicas que fluem e refluem, fazendo com que este terreno mude ao longo do tempo. Nos últimos anos, por exemplo, as questões ambientais ganharam maior relevância no cenário empresarial em função de diversos fatores, tais como a preocupação da sociedade com o aquecimento global, a exaustão de recursos naturais não renováveis e as possíveis consequências negativas desses e outros fenômenos para humanidade. 
Nesse cenário, emerge a chamada contabilidade social, que, de acordo com Gray (2002), leva uma grande variedade de formas e aparece com vários nomes. É usada como um termo genérico para cobrir todas as formas de evidenciação que vão além do sentido puramente econômico, a exemplo da responsabilidade social corporativa, auditorias sociais, comunicação social corporativa, relatório de emprego, relatórios dirigidos aos stakeholders, incluindo nessa relação a própria contabilidade ambiental.

Para Clarkson, Richardson e Vasvari (2007), a pesquisa na área da contabilidade socioambiental pode ser categorizada em três grupos: o primeiro grupo avalia a relevância da informação para performance ambiental corporativa; o segundo, examina os fatores que impactam a decisão gerencial em divulgar informações sobre o passivo ambiental; e o terceiro grupo identifica se há uma relação entre a evidenciação de informações ambientais e a performance organizacional.

De acordo com Nascimento et al. (2009), diversas dessas pesquisas utilizaram a Teoria da Legitimidade, buscando explicar e predizer as práticas de evidenciação voluntária, relacionando-as com as expectativas da sociedade, os impactos ambientais, desastres ecológicos, a atuação de grupos ambientalistas e a pressão da comunidade. Dentre os principais pesquisadores que contribuíram para o desenvolvimento de pesquisas nessa perspectiva, destacam-se Wilmshurt e Frost (2000), Milne e Patten (2002), O'donovan (2002), Villiers e Staden (2006); Patten e Cho (2007).

Essa crescente preocupação da sociedade por questões socioambientais tem motivado as empresas a investirem na divulgação desse tipo de informação. Pois, apesar da falta de obrigatoriedade para a evidenciação de informações ambientais, não evidenciá-las tornou-se uma desvantagem competitiva (MUSSOI; VAN BELLEN, 2010).

Nesse sentido, o aumento no volume de informações socioambientais de caráter voluntário tem funcionado como instrumento de legitimação para diversas empresas, uma vez que a divulgação de tais informações objetiva evidenciar que as companhias possuem responsabilidade social corporativa. Nesta perspectiva, Mayer e Rowan (1977) afirmam que as organizações alinhadas a regras institucionalizadas tendem a ganhar legitimidade e aumentam suas chances de sobrevivência.

Segundo Patten (1992), as empresas que tem sua legitimidade ameaçada por questões internas ou externas são mais propensas a adotar medidas de recuperação para legitimar suas atividades. Nesse sentido, Deegan e Rankin (1996), analisando as práticas de divulgação de informações ambientais de empresas australianas acionadas judicialmente por questões de crimes ambientais, constataram que houve um aumento na divulgação de informações ambientais naquelas que se envolveram em processos judiciais dessa natureza.

A maioria destes estudos utiliza a teoria da legitimidade para explicar e predizer as diferenças no conteúdo, na apresentação e no volume das divulgações 
desta natureza, ou seja, analisam o conteúdo desses relatórios sob parâmetros estabelecidos pela referida Teoria. Segundo O'Dwyer (2002), poucos estudos utilizam a perspectiva puramente gerencial para compreender a divulgação de informações socioambientais.

Wilmshurst e Frost (2000), ao investigar quais influências os gestores sofrem na hora de divulgar informações ambientais, identificaram que os principais fatores foram o direito dos investidores e acionistas às informações, as obrigações legais e a preocupação com a comunidade. Além destes fatores, os autores identificaram ainda o interesse e a preocupação com clientes, fornecedores, comunidade, instituições financeiras e também com a possibilidade de manter ou construir uma imagem positiva para a empresa.

No Brasil, nenhum estudo foi realizado buscando identificar a percepção dos gestores com a evidenciação voluntária de informações socioambientais. Portanto, analisar os fatores que impactam este tipo de divulgação, na percepção dos gestores, é assunto de considerável interesse para a pesquisa em contabilidade tendo em vista que a decisão de divulgar ou não essas informações é feita pela administração da empresa.

Nesse sentido, levando em consideração que o comportamento dos gestores pode ser mediado e influenciado por mecanismos institucionalizados, o presente estudo está orientado para responder à seguinte questão: Quais fatores impactam a divulgação voluntária de informações socioambientais na percepção dos gestores?

A partir das considerações acima apresentadas, esta pesquisa objetiva identificar quais os fatores que impactam a divulgação voluntária de informações socioambientais na percepção dos gestores das maiores companhias de energia elétrica do Brasil. A escolha da amostra deu-se em função destas companhias possuírem um programa formal de Responsabilidade Social Corporativa (RSC), evidenciando, anualmente, Relatório de Sustentabilidade e Global Reporting Initiative (GRI). Além disso, quatro das cinco companhias negociam Crédito de Carbono e Mecanismo de Desenvolvimento Limpo (MDL).

Esse estudo contribuirá para fortalecer e ampliar a discussão acerca do uso da teoria da legitimidade, notadamente no que diz respeito à capacidade de explicar e predizer fatores que influenciam a divulgação voluntária de informações socioambientais e, consequentemente, suas implicações sobre os usuários da contabilidade. Assim, consideramos que este trabalho é inovador, pois utiliza a perspectiva interna das organizações para investigar os potenciais mecanismos da contabilidade socioambiental, dirigindo a atenção para o problema da responsabilidade social corporativa com maior profundidade.

As questões associadas às motivações que explicam a decisão dos gestores de divulgar publicamente as informações sociais e ambientais é considerada por Deegan (2002) como uma boa oportunidade de pesquisa, pois fornece uma visão geral de vários fatores que poderiam ser atribuídos à decisão de divulgar informações sociais e ambientais. 
O presente artigo está dividido em cinco seções. Na primeira, tem-se a introdução, que busca apresentar e contextualizar o problema de que se ocupa a pesquisa, seus objetivos e relevância. A segunda seção traz a fundamentação teórica utilizada no desenvolvimento da pesquisa. O terceiro segmento, apresenta a metodologia utilizada na pesquisa empírica. Em seguida, a quarta seção apresenta à análise dos dados. Por fim, o quinto segmento apresenta as considerações finais sobre o estudo e formula sugestões para pesquisas futuras.

\section{FUNDAMENTAÇÃO TEÓRICA}

Nos tópicos seguintes, apresenta-se a base teórica desta pesquisa, e, complementarmente, uma revisão da literatura acerca do tema explorado.

\subsection{Teoria institucional e teoria da legitimidade}

De acordo com Iudícibus (2010), a contabilidade não pode ser totalmente bem entendida fora do contexto das organizações e de suas metas, as quais nem sempre são as da racionalidade absoluta e da busca da maior eficiência, como objetivos em si. A percepção de que as aplicações e características dos mecanismos contábeis nem sempre são definidas por motivações objetivas e racionais, especialmente quando se trata de fixação de normas e escolha de métodos, é a proposta da Teoria Institucional para o estudo da contabilidade.

Corroborando com esta percepção, Dias Filho e Machado (2004) afirmam que a Teoria Institucional nos ajuda a compreender que valores sociais (práticas, crenças, obrigações) assumem a condição de regra no pensamento e na ação dos indivíduos, estejam eles aglutinados numa organização ou dispersos na sociedade de forma geral. Com base nisso, as organizações nem sempre adotam este ou aquele procedimento por considerá-lo o mais racional em dada circunstância.

A Teoria Institucional indica que as organizações são levadas a incorporar as práticas e procedimentos definidos por conceitos racionalizados de trabalho organizacional prevalecentes e institucionalizados na sociedade. As organizações que fazem isto aumentam sua legitimidade e suas perspectivas de sobrevivência, independentemente da eficácia imediata das práticas e procedimentos adotados. Nesse sentido, determinadas práticas contábeis consideradas como legítimas pela sociedade podem até ser adotadas pelas empresas sem uma análise racional dos instrumentos que estão incorporando (TOLBERT; ZUCKER, 2009).

A noção de legitimidade é central para a teoria institucional. Os pesquisadores institucionais retratam legitimidade como um conjunto de crenças, onde as definições culturais determinam como a organização é construída e, simultaneamente, como ela é entendida e avaliada (DIMAGGIO; POWELL, 1983; MEYER; ROWAN, 1977). Dentro dessa concepção, legitimidade e institucionalização são praticamente sinônimos (SHUCHMAN, 1995). 
A teoria da legitimidade prevê que as empresas tendem a fazer o que consideram necessário para preservar a sua imagem de empresa legítima, com fins legítimos. Essa teoria é utilizada principalmente na pesquisa em contabilidade social e ambiental, apoiando a idéia de que as divulgações sociais serão mantidas nos níveis atuais, ou alteradas ao longo do tempo, para evitar crises de legitimidade (VILLIERS; STADEN, 2006).

Em uma sociedade dinâmica, nem as fontes de poder institucional, nem as necessidades de seus serviços são permanentes. Portanto, a instituição deve se manter atenta para a necessidade de realizar, periodicamente, testes individuais de legitimidade e relevância, a fim de saber o que a sociedade realmente exige de seus serviços (DEEGAN, 2002).

As mudanças nas normas e valores sociais são fatores motivadores para a organização mudar e também representam uma fonte de pressão para a legitimação organizacional (O'DONOVAN, 2002). O status de legitimidade organizacional pode ser difícil de se estabelecer uma vez que a legitimidade de uma corporação é baseada em percepções e valores sociais que podem mudar ao longo do tempo. Por isso, para gerir a legitimidade organizacional, as empresas precisam saber como podem adquirir, manter ou perder a legitimidade.

A evidenciação de informações socioambientais é feita, em sua maioria, de forma voluntária. Por isso, grande parte das pesquisas contábeis nessa área tenta explicar e predizer as diferenças no conteúdo, na apresentação e no volume das divulgações dessa natureza. A literatura sugere que a evidenciação voluntária de informações socioambientais, através do relatório anual corporativo, pode ajudar a resolver alguns dos problemas que cercam a realização de legitimidade organizacional (DEEGAN, 2002).

A teoria da legitimidade tem sido muito utilizada nesses estudos, apoiando a idéia de que as divulgações de informações socioambientais serão mantidas ou alteradas ao longo do tempo para evitar crises de legitimidade. De acordo com Belal e Owen (2007), inicialmente, estas pesquisas analisaram o conteúdo desses relatórios, com perspectivas de aumentar a legitimidade das partes interessadas, na tentativa de explicar a prática, ao invés de simplesmente descrevê-la.. Confirmando que tais relatórios geralmente são utilizadados com o propósito de produzir ou aumentar legitimidade no âmbito corporativo, temos os trabalhos de Deegan (2002), Deegan e Gordon (1996), Deegan e Ranking (1996), O’Donovan (2002) e Patten (1992).

Deegan e Rankin (1996) verificaram que as empresas são mais propensas a apresentar informações em seus relatórios ambientais que sejam favoráveis à sua imagem corporativa e tendem a omitir informações de natureza negativa que possam impactar em sua legitimidade perante a sociedade.

Nesse contexto, Patten e Cho (2007) afirmam que a Teoria da Legitimidade sugere que a divulgação e extensão de informações socioambientais é uma função de exposição à pressão da opinião pública no ambiente social e político. Com base nessa teoria, as empresas que enfrentam uma maior exposição ao julgamento da sociedade, 
como as empresas com pior desempenho ambiental, forneceriam mais ampla compensação ou divulgações ambientais positivas, numa tentativa de conter ameaças à sua legitimidade. Este estudo comprovou que a divulgação ambiental é utilizada como uma ferramenta de legitimidade.

Sendo assim, a teoria da legitimidade é relevante para explicar os fatores que levam as organizações a divulgarem voluntariamente informações socioambientais. Isto porque as empresas que pretendem se estabelecer no mercado geralmente buscam equilíbrio entre os valores sociais integrados às suas operações e as normas sociais ou de comportamento aceitáveis no sistema social de que fazem parte (DEEGAN, 2002). As perspectivas fornecidas pela teoria da legitimidade indicam que as organizações fazem parte de um sistema social e existem na medida em que a sociedade considera que elas são legítimas e necessárias.

Segundo Deegan (2002), a literatura atual fornece indicações de que a evidenciação social e ambiental é motivada por um desejo da administração em legitimar vários aspectos de suas respectivas organizações. Nesse sentido, os gestores tendem a utilizar os relatórios socioambientais como uma estratégia organizacional para manter a sua sobrevivência.

\subsection{Fatores gerenciais para a divulgação de informações socioambientais}

A iniciativa para a doção de práticas de sustentabilidade é uma decisão organizacional levada a termo pela alta administração. A inclusão do desenvolvimento sustentável nas estratégias e práticas organizacionais pressupõe a identificação e a análise das características organizacionais, o indispensável aporte de recursos, meios que afetarão o modelo de gestão e, certamente, a cultura institucional e, ainda, o comportamento de dirigentes e colaboradores. (FURTADO, 2005)

Segundo Deegan (2002), há uma variedade de fatores que influenciam os gestores a evidenciar voluntariamente as informações socioambientais. Dentre os principais, podemos citar: cumprir com os requisitos legais; racionalidade econômica; prestar contas ou responsabilidade de informar; cumprir com as necessidades de financiamento; cumprir com as expectativas da comunidade; responder a certas ameaças à legitimidade da organização; gerenciar grupos de interesse particulares; atrair fundos de investimento; atender aos requisitos da indústria, ou códigos de conduta; evitar esforços de introduzir regras de divulgação mais onerosas; ganhar prêmios de relatórios específicos.

Deegan (2002) afirma ainda que a organização poderia ser motivada pelo desejo de prestar contas em relação a seu desenvolvimento social e ambiental, mas esperar que esta motivação predomine sobre todas as outras seria irrealista.

Adams (2002) dividiu os fatores internos para divulgação de informações socioambientais em duas categorias: 1) o processo de comunicação, que são a 
comissão social corporativa, balanço social corporativo, estrutura societária e os procedimentos de governança, o processo de organização de relatórios, mídia utilizada para comunicar o relatório de sustentabilidade, diretrizes para relatórios de sustentabilidade, a extensão e a natureza da participação dos stakeholders e a extensão do envolvimento dos contadores; e, 2) as atitudes corporativas são os pontos de vista sobre o aumento recente dos relatórios e inclui a comparação com os relatórios de sustentabilidade de outras empresas, o relato das más notícias, divulgação de relatórios no futuro, a regulação e verificação, os custos e benefícios percebidos da comunicação e a cultura corporativa.

Segundo esta autora, muitos dos fatores contextuais internos são influenciados por variáveis contextuais gerais, tais como o contexto político, social e econômico. Adams identificou que o processo de comunicação parece depender também do país de origem, do tamanho das empresas e da cultura. Aspectos do processo que parecem ser influenciados por essas variáveis são o grau de formalidade/informalidade dos departamentos envolvidos na elaboração do relatório de RSC e o envolvimento dos stakeholders (ADAMS, 2002). A autora ressalta, ainda, que é importante ter em mente que o processo em que as variáveis mencionadas influenciam a extensão e natureza da RSC é dinâmica. Não existe uma explicação de como, por exemplo, o tamanho das empresas afeta a divulgação de RSC pois ela pode variar amplamente, dependendo do aparecimento de outros elementos. Os fatores apresentados por Adams (2002) serão relacionados na figura 1, a seguir.

Figura 1 - Representação esquemática das influências na comunicação social corporativa

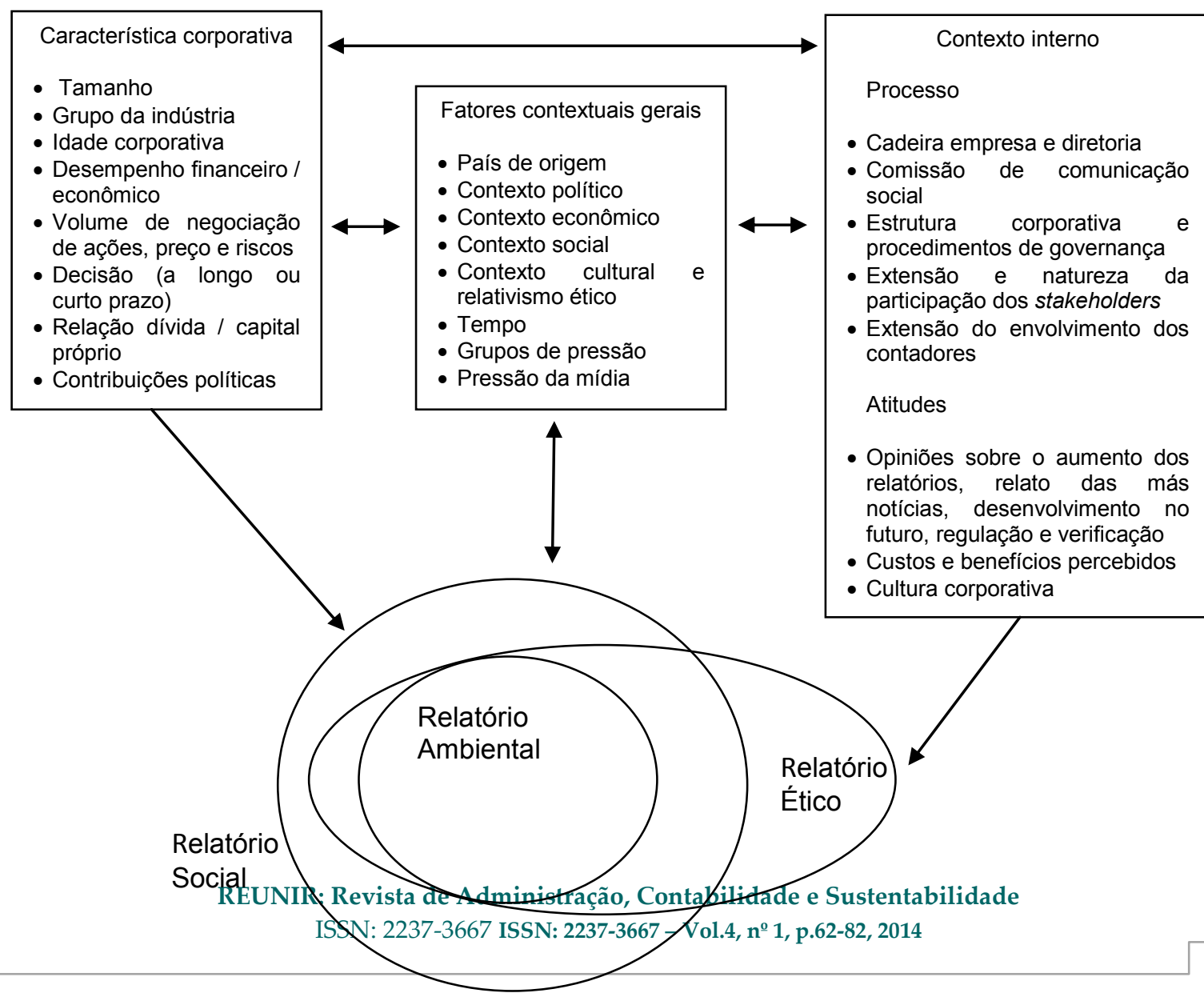


Fonte: Adams (2002, p. 246)

Poucos estudos tem procurado oferecer explicações para as decisões corporativas em evidenciar informações socioambientais em seus relatórios anuais utilizando a perspectiva gerencial (O'DWYER, 2002). As pesquisas nessa área buscam analisar as motivações da gestão em evidenciar informações socioambientais, mais diretamente através da utilização do método de entrevista. Confirmam esta atitude os trabalhos de Adams (2002), Belal e Owen (2007), O’Donovan (2002), O'Dwyer (2002, 2003) e Wilmshurst e Frost (2000). Nesse sentido, alguns estudos buscam identificar os fatores gerenciais determinantes da evidenciação voluntária de informações sociais lastreando-se na teoria da legitimidade (BELAL E OWEN, 2007; O'DWYER, 2002; O'DWYER, 2003).

Wilmshurst e Frost (2000) ao investigar quais influências os gestores sofrem na hora de divulgar informações ambientais, identificaram que os principais fatores foram o direito dos investidores e acionistas às informações, as obrigações legais e a preocupação com a comunidade. Além destes, os autores identificaram ainda o interesse e a preocupação com clientes, fornecedores, comunidade, instituições financeiras e a também com uma imagem positiva da empresa.

Adams (2002) ao entrevistar indivíduos de três empresas britânicas e quatro empresas alemãs, nos setores químico e farmacêutico, identificou que a principal motivação para empresas divulgarem informações sociais é melhorar a imagem corporativa e a credibilidade com as partes interessadas. Além disso, a autora identificou que a principal razão para iniciar o relatório foi a pressão da opinião pública. Esta foi também uma razão importante para a evolução e a introdução de mudanças na comunicação prática. Entre os entrevistados, há um consenso geral de que relatar uma má notícia reforça a credibilidade e a imagem corporativa. Houve também alguma preocupação com a reação do público às divulgações sobre assuntos específicos, tais como multas. Este medo de reações desconhecidas, segundo Adams (2002), explica a pequena quantidade de informações que expressam más notícias nos relatórios dessas empresas.

O'dwyer (2002), através de entrevistas com gerentes na Irlanda, identificou que o principal fator para divulgação voluntária de informações socioambientais foi a pressão social externa - exercidas pela comunidade, grupos ambientais e meios de comunicação - que possuía forte potencial para prejudicar os interesses econômicos da organização. Além disso, O'dwyer (2002) encontrou evidências de que a maioria das empresas estava interessada em serem vistas com algum tipo de consciência social, seja sobre meio ambiente, segurança no trabalho etc. Na percepção dos 
gestores entrevistados, reagir a determinadas preocupações sociais ou ambientais por divulgações pode contribuir para legitimar a organização. No entanto, quando essas evidenciações são percebidas como inúteis para a estratégia de legitimação, os gestores desistem de algumas formas de divulgação ambiental (O'DWYER, 2002).

O'dwyer (2003) elenca três principais justificativas que sustentam a aceitação da responsabilidade social corporativa, segundo a percepção dos grandes executivos da Irlanda, a saber: 1) interesse próprio esclarecido proativo; 2) interesse próprio esclarecido reativo; e 3) obrigações/deveres.

Em relação a primeira justificativa, ação proativa, O'dwyer (2003) identificou que o auto interesse econômico e o de melhorar a marca e a imagem da empresa foram considerados os principais fatores para a evidenciação de informações socioambientais. A maioria dos gestores entrevistados concordou que a gestão eficaz das questões sociais permite a organização cumprir o seu objetivo primário de maximizar o valor do acionista. Alguns gestores afirmaram ainda que o papel social e econômico de uma organização não deve ser visto como estando em conflito, pois eles são complementares e não incompatíveis.

$\mathrm{Na}$ segunda justificativa, ação reativa, O'dwyer (2003) identificou que o principal fator para a evidenciação voluntária de informações socioambientais é a pressão externa imposta às empresas que decorrem muitas vezes das comunidades locais, grupos de pressão e dos meios de comunicação. Nesse sentido, as empresas de setores com maior impacto ambiental publicamente percebido tendem a ser muito sensíveis às pressões sociais externas.

A terceira justificativa, obrigações/deveres segundo O'dwyer (2003), inicialmente foi proferida de maneira geral como resultante de uma perspectiva ampla moralista e foi percebida pelo entrevistador como independentemente de qualquer conseqüência econômica. No entanto, essa percepção é contraditória, pois ao mesmo tempo em que os gerentes afirmaram que as obrigações são devidas a toda a sociedade, independentemente dos impactos econômicos, defenderam que a responsabilidade social corporativa apoiava os objetivos econômicos da organização a fim de ser amplamente aceita.

O'Dwyer, Unerman e Bradley (2005) buscaram compreender o surgimento e o futuro desenvolvimento da divulgação social nas empresas irlandesas. Para isso, os autores entrevistaram oito líderes de Organizações não governamentais (ONGs) ambientais e sociais. Os resultados indicam que a responsabilidade social corporativa foi motivada pelo reconhecimento dos direitos da sociedade pelas informações sociais e ambientais e, também, pelo desejo de melhorar o desempenho corporativo social e ambiental. Nesse contexto, as empresas foram consideradas como tendo obrigação para fornecer informações sobre os impactos sociais e ambientais pata todos os stakeholders. Grande parte dos entrevistados concordou ainda que, para aumentar a transparência corporativa, as empresas deveriam ser obrigadas a melhorar o seu desempenho social e ambiental. As perspectivas acima têm amplas implicações para o desenvolvimento do futuro da responsabilidade social 
corporativa na Irlanda, tendo em vista que as empresas irlandesas divulgam seus relatórios sociais e ambientais voluntariamente. No entanto, a comunicação obrigatória tem pouco apoio em nível governamental.

Belal e Owen (2007), examinando o ponto de vista dos gestores de Bangladesh, identificaram que a evidenciação voluntaria de informações socioambientais foi impulsionada pela preocupação de melhorar a imagem da empresa e pela pressão externa exercida principalmente pelos financiadores de capital e compradores internacionais. Além disso, os autores identificaram que os entrevistados de empresas multinacionais pareciam muito mais conscientes das influências internas decorrentes de uma necessidade de manter boas relações com o governo e atrair funcionários devidamente qualificados. Um pequeno número de entrevistados apontou ainda a influência de ONG's nacionais e órgãos comunitários. Neste estudo, poucos entrevistados fizeram menção específica à necessidade de atender às prioridades sociais.

Diante do exposto, observa-se que a exploração dos fatores gerenciais para a divulgação de informações socioambientais tem posição de destaque dentro da comunicação social corporativa. Esta análise através da perspectiva da legitimidade é bastante relevante, pois busca explicar a prática, ao invés de simplesmente descrevêla.

\section{MÉTODO DE PESQUISA}

Esta pesquisa teve como objetivo identificar quais fatores influenciam a divulgação voluntária de informações socioambientais na percepção dos gestores das maiores companhias de energia elétrica do país. Em função deste objetivo, e baseando-se em Gil (2002), entendemos que esta pesquisa pode ser classificada como descritiva, pois procura descrever as características de determinadas populações ou fenômenos.

Quanto aos procedimentos, o presente estudo se caracteriza como levantamento. Conforme Santos (2001), esse tipo de pesquisa busca informação diretamente com um grupo de interesse a respeito dos dados que se deseja obter. $\mathrm{O}$ levantamento é geralmente desenvolvido em três etapas: seleciona-se uma amostra significativa, aplicam-se questionários, formulários ou entrevistam-se diretamente os indivíduos; os dados são tabulados e analisados quantitativamente, com o auxílio de cálculos estatísticos; os resultados obtidos são, então, aplicados, com margem de erro estatisticamente prevista, ao universo gerador da amostra (SANTOS, 2001).

A população escolhida para investigação foi constituída pelo conjunto de companhias classificadas entre as 500 maiores empresas do Brasil por faturamento, segundo a Revista Exame (2010). A partir dela, delimitou-se a amostra selecionando as 10 maiores empresas atuantes no setor de energia elétrica. Em seguida, essas empresas foram contatadas por telefone e convidadas a participar da pesquisa. Do 
total das 10 empresas listadas na base de dados consultada, 5 concordaram em participar da investigação e responderam ao questionário.

O questionário utilizado para coleta dos dados desta pesquisa foi composto de três partes, seguindo as justificativas apresentadas por O'dwyer (2003): 1) interesse próprio esclarecido proativo; 2) interesse próprio esclarecido reativo; e 3) obrigações/deveres. As questões inseridas em cada seção foram baseadas nas respostas apresentadas nos trabalhos de O'dwyer (2002), O'dwyer, (2003) e Belal e Owen (2007). No entanto, tendo em vista que essas pesquisas foram qualitativas, feitas através de entrevista, optou-se por deixar um espaço em branco ao final de cada parte, caso o gestor tivesse interesse em acrescentar outros fatores.

A escolha do questionário como instrumento de coleta de dados foi motivada pela distância geográfica existente entre as sedes das companhias de eletricidade do Brasil, fator que tornou inviável a opção pela entrevista. Nesse sentido, foram elaboradas 27 questões assertivas de múltiplas alternativas, que foram dispostas em escala Likert de 1 a 5. Nesta dimensão, pode-se imaginar uma escala contínua que apresenta em cada um dos pólos uma das duas categorias: discordo totalmente e concordo totalmente.

O questionário foi disponibilizado on-line no Google Docs. Os dados foram submetidos ao Statistical Package for Social Sciences (SPSS), versão 15.0 e analisados utilizando o teste não paramétrico de Kruskall-Wallis, com a finalidade de comparar a média das respostas dos entrevistados. De acordo com Bruni (2009), este teste deve ser empregado na análise do fato de $\mathrm{K}(\mathrm{K}>2)$ amostras, independentemente de serem ou não originárias de populações com médias iguais.

Após a análise estatística, os resultados foram interpretados à luz do referencial teórico apresentado, para em seguida tecermos considerações acerca dos resultados encontrados..

\section{APRESENTAÇÃO E ANÁLISE DOS RESULTADOS}

A presente análise estatística teve como objetivos principais: (1) apresentar o perfil da amostra pesquisada e (2) comparar as respostas dos pesquisados dispostas na escala Likert. Para isso, foi utilizado o teste de Kruskall-Wallis para as variáveis não consideradas normais. Para relacionar às dimensões do escalonamento às assertivas da escala Likert, procedeu-se ao agrupamento das assertivas em três diferentes categorias, discordo (1 a 3), neutro (4) e concordo (5 a 7). O questionário foi aplicado a cinco gestores de companhias de energia elétrica do país, os quais trabalham diretamente com o setor de meio ambiente. Constatou-se que todos possuem nível superior, sendo que três são graduados em contabilidade, um é graduado em economia e o outro, em engenharia elétrica. Além disso, todos os gestores são pós-graduados. 
Tendo em vista, o tamanho reduzido da amostra, foi utilizado o teste de Kruskal Wallis para fazer as comparações das respostas dos pesquisados. Os resultados deste teste são apresentados a seguir:

Tabela 1 - Teste de Kruskall-Wallis.

\begin{tabular}{|l|c|c|c|}
\hline \multicolumn{1}{|c|}{ Assertivas } & $\begin{array}{c}\text { Qui- } \\
\text { Quadrado }\end{array}$ & $\begin{array}{c}\text { Graus de } \\
\text { Liberdade }\end{array}$ & Significância \\
\hline 1. Maximizar o valor para o acionista & 4,000 & 4 & 0,406 \\
\hline 2. Melhorar a imagem da empresa perante a sociedade & 4,000 & 4 & 0,406 \\
\hline 3. Aumentar a valor das ações da empresa & 4,000 & 4 & 0,406 \\
\hline $\begin{array}{l}\text { 4. Promover uma reputação de comunicação confiável } \\
\text { e transparente }\end{array}$ & 4,000 & 4 & 0,406 \\
\hline $\begin{array}{l}\text { 5. Oportunizar novas fontes de financiamento e } \\
\text { capital }\end{array}$ & 4,000 & 4 & 0,406 \\
\hline 6. Obter incentivos fiscais e políticas públicas & 4,000 & 4 & 0,406 \\
\hline 7. Reduzir o custo de capital & 4,000 & 4 & 0,406 \\
\hline 8. Manter a posição competitiva da empresa & 4,000 & 4 & 0,406 \\
\hline 9. Reduzir o risco de possíveis ações & 4,000 & 4 & 0,406 \\
\hline $\begin{array}{l}\text { 10. Evitar impactos ambientais potencialmente } \\
\text { danosos }\end{array}$ & 4,000 & 4 & 0,406 \\
\hline 11. Antecipar-se aos requisitos legalmente impostos & 4,000 & 4 & 0,406 \\
\hline
\end{tabular}

Fonte: Dados da pesquisa.

A Tabela 1 visa identificar a percepção dos gestores em relação aos fatores relacionados com a primeira justificativa apresentada por O'dwyer (2003), interesse próprio esclarecido proativo. A análise desse quadro permitiu identificar que a significância do teste de Kruskall-Wallis apresentou o valor 0,406 para todas as assertivas. Tendo em vista que esse valor é superior a 0,05 , conclui-se que as opiniões dos gestores pesquisados em relação às variáveis apresentadas abaixo não apresentam diferenças significativas.

Para analisar mais detalhadamente, agruparam-se as opiniões dos gestores em relação a esses quesitos na Tabela 2. Nesse sentido, a frequência das respostas "discordo totalmente" e "discordo parcialmente" foram agrupadas como "discordo" e as opções "concordo totalmente" e "concordo parcialmente" como concordo.

Tabela 2 - Frequência das Respostas.

\begin{tabular}{|l|c|c|c|}
\hline \multicolumn{1}{|c|}{ Assertivas } & Discordo & Neutro & Concordo \\
\hline 1. Maximizar o valor para o acionista & 1 & 0 & 4 \\
\hline 2. Melhorar a imagem da empresa perante a sociedade & 0 & 0 & 5 \\
\hline 3. Aumentar a valor das ações da empresa & 1 & 1 & 3 \\
\hline $\begin{array}{l}\text { 4. Promover uma reputação de comunicação confiável } \\
\text { e transparente }\end{array}$ & 0 & 0 & 5 \\
\hline $\begin{array}{l}\text { 5. Oportunizar novas fontes de financiamento e } \\
\text { capital }\end{array}$ & 1 & 0 & 4 \\
\hline 6. Obter incentivos fiscais e políticas públicas & 0 & 2 & 3 \\
\hline 7. Reduzir o custo de capital & 1 & 2 & 2 \\
\hline
\end{tabular}




\begin{tabular}{|l|l|l|l|}
\hline 8. Manter a posição competitiva da empresa & 0 & 0 & 5 \\
\hline 9. Reduzir o risco de possíveis ações econômicos potencialmente & 2 & 0 & 5 \\
\hline $\begin{array}{l}\text { 10. Evitar impactos ecostos } \\
\text { danosos }\end{array}$ & 0 & 2 & 3 \\
\hline 11. Antecipar-se aos requisitos legalmente impostos & 0 & 3 \\
\hline
\end{tabular}

Fonte: Dados da pesquisa.

A partir da análise da tabela 2, constatou-se que os pesquisados tendem a concordar com todas as assertivas exceto a 7. Nesse sentido, a maioria dos gestores concordam que a evidenciação voluntária de informações socioambientais maximiza o valor para o acionista (assertiva 1), melhora a imagem da empresa (assertiva 2), aumenta o valor das ações da empresa (assertiva 3), promove uma reputação de comunicação confiável e transparente (assertiva 4), oportuniza novas fontes de financiamento e capital (assertiva 5), oportuniza a obtenção de incentivos fiscais e políticas públicas (assertiva 6), mantém a posição competitiva da empresa (assertiva 8), reduz o risco de possíveis ações (assertiva 9), evita impactos econômicos potencialmente danosos (assertiva 10) e permite a companhia antecipar-se aos requisitos legalmente impostos (assertiva 11).

As opiniões expressas pelos gestores corroboram com os estudos considerados anteriormente, O'dwyer (2002), O'dwyer (2003), Belal e Owen (2007). Nesse sentido, pode-se afirmar com propriedade que, na percepção dos pesquisados, os fatores proativos que mais impactam a evidenciação voluntária de informações socioambientais são as preocupações com a imagem da empresa, a competitividade empresarial, a redução do risco de possíveis ações, a maximização do valor do acionista, a oportunidade de novas fontes de financiamento, a valorização das ações, evitar impactos econômicos potencialmente danosos e a antecipação aos requisitos legalmente impostos.

Esse resultado é consistente com a teoria da legitimidade, tendo em vista que a evidenciação de tais informações pode contribuir para fortalecer a imagem da empresa, garantindo sua prosperidade ou, até mesmo, sua sobrevivência. Isso sugere que a evidenciação socioambiental é utilizada para construir uma imagem de organização socialmente responsável.

A teoria da legitimidade também prevê que a escolha dos métodos contábeis é influenciada pelo ambiente político, econômico e institucional em que opera a organização (Miller, 1994). Portanto, a influência dos grupos de interesse, também pode ser considerada um fator para manter a legitimidade organizacional. Buscou-se identificar através das assertivas 12 a 23 se alguns desses grupos de interesse influenciam, na percepção dos gestores, o disclosure de informações socioambientais das companhias pesquisadas.

A tabela 3 tem por finalidade identificar a percepção dos gestores em relação aos fatores relacionados com a segunda justificativa apresentada por O'dwyer (2003), interesse próprio esclarecido reativo. A análise desse quadro permitiu identificar que a significância do teste de Kruskall-Wallis apresentou o valor 0,406 para todas as 
assertivas. Tendo em vista que esse valor é superior a 0,05, conclui-se que as opiniões dos gestores pesquisados em relação às variáveis apresentadas abaixo não apresentam diferenças significativas.

Tabela 3 - Teste de Kruskall-Wallis.

\begin{tabular}{|c|c|c|c|}
\hline Assertivas & $\begin{array}{c}\text { Qui- } \\
\text { Quadrado }\end{array}$ & $\begin{array}{c}\text { Graus de } \\
\text { Liberdade }\end{array}$ & Significância \\
\hline 12. Pressão exercida pelos dos agentes reguladores & 4,000 & 4 & 0,406 \\
\hline 13. Pressão exercida pelos acionistas & 4,000 & 4 & 0,406 \\
\hline 14. Pressão exercida pelas ONG's & 4,000 & 4 & 0,406 \\
\hline 15. Pressão exercida pela comunidade & 4,000 & 4 & 0,406 \\
\hline 16. Pressão exercida pelos financiadores de capital & 4,000 & 4 & 0,406 \\
\hline 17. Pressão exercida pelos clientes & 4,000 & 4 & 0,406 \\
\hline $\begin{array}{l}\text { 18. Pressão exercida pela mídia } \\
\text { comunicação) }\end{array}$ & 4,000 & 4 & 0,406 \\
\hline 19. Pressão exercida pelos grupos ambientais & 4,000 & 4 & 0,406 \\
\hline 20. Pressão exercida pelo governo & 4,000 & 4 & 0,406 \\
\hline 21. Pressão exercida pelos credores & 4,000 & 4 & 0,406 \\
\hline 22. Pressão exercida pelos funcionários & 4,000 & 4 & 0,406 \\
\hline 23. Pressão exercida pelos grupos de lobby ambiental & 4,000 & 4 & 0,406 \\
\hline
\end{tabular}

Fonte: Dados da pesquisa.

Para analisar mais detalhadamente, as opiniões dos gestores foram agrupadas em relação a esses quesitos na Tabela 4. Nesse sentido, a frequência das respostas "discordo totalmente" e "discordo parcialmente" foram agrupadas como "discordo" e as opções "concordo totalmente" e "concordo parcialmente", como concordo.

Tabela 4 - Frequência das Respostas.

\begin{tabular}{|c|c|c|c|}
\hline Assertivas & Discordo & Neutro & Concordo \\
\hline 12. Pressão exercida pelos dos agentes reguladores & 1 & 1 & 3 \\
\hline 13. Pressão exercida pelos acionistas & 2 & 0 & 3 \\
\hline 14. Pressão exercida pelas ONG's & 2 & 1 & 2 \\
\hline 15. Pressão exercida pela comunidade & 1 & 0 & 3 \\
\hline 16. Pressão exercida pelos financiadores de capital & 1 & 1 & 3 \\
\hline 17. Pressão exercida pelos clientes & 1 & 0 & 3 \\
\hline $\begin{array}{c}\text { 18. Pressão exercida pela mídia (meios de } \\
\text { comunicação) }\end{array}$ & 0 & 2 & 3 \\
\hline 19. Pressão exercida pelos grupos ambientais & 3 & 0 & 2 \\
\hline 20. Pressão exercida pelo governo & 1 & 1 & 3 \\
\hline 21. Pressão exercida pelos credores & 1 & 0 & 4 \\
\hline 22. Pressão exercida pelos funcionários & 1 & 0 & 4 \\
\hline 23. Pressão exercida pelos grupos de lobby ambiental & 2 & 2 & 1 \\
\hline
\end{tabular}

Fonte: Dados da pesquisa.

A partir da análise da Tabela 4, constatou-se que os pesquisados tendem a concordar com todas as assertivas exceto a 14, 19 e 23 . Nesse sentido, a maioria dos 
gestores concorda que as principais fontes de pressões sociais para evidenciação voluntária de informações socioambientais são as exercidas pelos agentes reguladores (assertiva 12), acionistas (assertiva 13), comunidade (assertiva 15), financiadores de capital (assertiva 16), clientes (assertiva 17), mídia (assertiva 18), governo (assertiva 20), credores (assertiva 21) e funcionários (assertiva 22).

As opiniões expressas pelos gestores corroboram com os estudos considerados anteriormente, Wilmshurst e Frost (2000), O'dwyer (2002), O'dwyer (2003), Belal e Owen (2007). Nesse sentido, pode-se afirmar que, na percepção dos pesquisados, os fatores reativos que mais impactam a evidenciação voluntária de informações socioambientais são as pressões exercidas por credores, funcionários, agentes reguladores, acionistas, comunidade, financiadores de capital, clientes, mídia e governo. Esse resultado é consistente com a teoria da legitimidade, tendo em vista que, segundo Patten e Cho (2007), a divulgação e extensão de informações socioambientais é uma função de exposição às pressões estruturais encontradas por esses gestores no ambiente social e político.

Bucholz (1987 apud O'dwyer, 2003) argumentou que a responsabilidade é um termo moral e implica a obrigação de alguém ou de algo. O Quadro 5 tem por finalidade identificar a percepção dos gestores quanto aos fatores relacionados com a terceira justificativa apresentada por O'dwyer (2003), obrigação/deveres. Nesse sentido, a percepção dos gestores foi analisada nas assertivas focando a ampliação das responsabilidades das empresas no interesse da sociedade em geral.

A análise desse quadro permitiu identificar que a significância do teste de Kruskall-Wallis apresentou o valor 0,406 para todas as assertivas. Tendo em vista que esse valor é superior a 0,05 , conclui-se que as opiniões dos gestores pesquisados em relação às variáveis apresentadas abaixo não apresentam diferenças significativas.

Tabela 5 - Teste de Kruskall-Wallis.

\begin{tabular}{|l|c|c|c|}
\hline \multicolumn{1}{|c|}{ Assertivas } & $\begin{array}{c}\text { Qui- } \\
\text { Quadrado }\end{array}$ & $\begin{array}{c}\text { Graus de } \\
\text { Liberdade }\end{array}$ & Significância \\
\hline 24. Proteger o meio ambiente & 4,000 & 4 & 0,406 \\
\hline 25. Proteger o interesse do acionista & 4,000 & 4 & 0,406 \\
\hline 26. Contribuir para o desenvolvimento da sociedade & 4,000 & 4 & 0,406 \\
\hline $\begin{array}{l}\text { 27. Contribuir para o desenvolvimento dos } \\
\text { funcionários }\end{array}$ & 4,000 & 4 & 0,406 \\
\hline
\end{tabular}

Fonte: Dados da pesquisa.

Objetivando analisar mais detalhadamente, agruparam-se as opiniões dos gestores em relação a esses quesitos no Tabela 4. Nesse sentido, a frequência das respostas "discordo totalmente" e "discordo parcialmente" foram agrupadas como "discordo" e as opções "concordo totalmente" e "concordo parcialmente", como concordo. 


\begin{tabular}{|l|c|c|c|}
\hline \multicolumn{1}{|c|}{ Assertivas } & Discordo & Neutro & Concordo \\
\hline 24. Proteger o meio ambiente & 0 & 0 & 5 \\
\hline 25. Proteger o interesse do acionista & 1 & 0 & 4 \\
\hline 26. Contribuir para o desenvolvimento da sociedade & 0 & 0 & 5 \\
\hline $\begin{array}{l}\text { 27. Contribuir para o desenvolvimento dos } \\
\text { funcionários }\end{array}$ & 0 & 0 & 5 \\
\hline
\end{tabular}

As percepções dos gestores expressas na Tabela 6 corroboram com o estudo de O'dwyer (2003). Verifica-se que a maioria dos gestores concorda que a evidenciação voluntária de informações ambientais. Essa postura tem o sentido de proteger o meio ambiente, proteger o interesse do acionista, contribuir para o desenvolvimento da sociedade e dos funcionários. Deve-se ressaltar, entretanto, que, segundo O'dwyer (2003), a conotação moralista, obrigação e dever, muitas vezes é interpretada como sendo dependente e não independente do sucesso econômico.

Diante disso, verifica-se que a responsabilidade social empresarial faz parte da estratégia de negócio das empresas pesquisadas. Os resultados encontrados corroboram com o aparato conceitual da teoria da legitimidade. A análise de significância feita através do Teste de Kruskall-Wallis permitiu concluir que não há diferença significativa entre as médias para todas as assertivas propostas.

\section{CONSIDERAÇÕES FINAIS E SUGESTÕES PARA PESQUISAS FUTURAS}

Este estudo teve por objetivo identificar, com o aparato conceitual da Teoria da Legitimidade, quais fatores impactam a divulgação voluntária de informações socioambientais na percepção dos gestores. A teoria que fundamentou esta pesquisa nos permite considerar a hipótese de que a divulgação voluntária de informações socioambientais está associada à tentativa de construir, manter ou recuperar legitimidade organizacional, o que de fato se confirmou neste estudo. Nesse sentido, a pesquisa contribuiu para confirmar o poder preditivo e explicativo da Teoria da Legitimidade no campo da evidenciação contábil. Mais uma vez, fica comprovado que certas políticas de evidenciação contábil nem sempre são definidas pela efetiva necessidade de municiar o processo decisório, mas sim por pressões derivadas do ambiente em que a organização se encontra inserida. Como se demonstrou, neste estudo, isso tem acontecido com muita frequência quando se trata de mecanismos de evidenciação de cunho social e ambiental.

Os resultados da pesquisa apontam que os principais fatores que impactam a evidenciação voluntária de informações socioambientais são as preocupações com a imagem da empresa, a competitividade empresarial, a redução do risco de possíveis ações, a maximização do valor do acionista, a oportunidade de novas fontes de financiamento, a valorização das ações, evitar impactos econômicos potencialmente danosos e a antecipação aos requisitos legalmente impostos 
Tais achados são consistentes com o aparato conceitual da teoria da legitimidade, tendo em vista que, os gestores acreditam que a evidenciação de tais informações contribui para fortalecer a imagem da empresa. Isso sugere que a evidenciação socioambiental é utilizada para construir uma imagem de organização socialmente responsável. Verifica-se, também, que a responsabilidade social empresarial faz parte da estratégia de negócio destas companhias, garantindo sua posição competitiva, prosperidade, e até mesmo, sua sobrevivência no mercado.

A teoria da legitimidade prevê ainda que a divulgação e extensão de informações socioambientais é uma função de exposição às pressões estruturais encontradas por esses gestores no ambiente social e político (PATTEN; CHO, 2007). Nesse contexto, verifica-se que as companhias pesquisadas sofrem pressões dos credores, dos funcionários, dos agentes reguladores, dos acionistas, da comunidade, dos financiadores de capital, dos clientes, da mídia e do governo.

Os resultados deste estudo podem contribuir para uma melhor seleção dos stakeholders que devem se constituir em alvo preferencial das evidenciações de caráter social e ambiental. É importante salientar que não se trata de propor a exclusão de outras categorias de stakeholderes, a priori, mas de identificar os que mais demandam e valorizam esse tipo de evidenciação. Afinal, não se pode perder de vista que recursos econômicos são absorvidos pelo processo de evidenciação contábil e, portanto, é necessário identificar meios de maximizar sua utilidade.

De qualquer forma, observou-se que, em geral, os gestores concordam que a evidenciação voluntária de informações ambientais incorpora o sentido de proteger o meio ambiente, proteger o interesse do acionista, contribuir para o desenvolvimento da sociedade e dos funcionários. Sob essa perspectiva, considera-se que as obrigações de caráter socioambiental são vistas como devidas e, em última instância, colaboram para o sucesso do resultado econômico da empresa.

Deve-se ressaltar, entretanto, que pode haver outros fatores que não foram elencados neste trabalho e que também explicam a decisão dos gestores de lançar mão de certos mecanismos de evidenciação de cunho social e ambiental. No entanto, pode-se afirmar com propriedade, que um fator que engloba todos os demais no contexto da RSC das empresas é o desejo da organização em legitimar suas atividades. Esta visão é perfeitamente congruente com os pressupostos da teoria da legitimidade.

À guisa de conclusão, reafirmamos que os resultados da pesquisa corroboram com o aparato conceitual da teoria da legitimidade. Comprovou-se, mais uma vez, que ela fornece uma substrato útil para a investigação de estudos dentro da área de RSC. Além disso, as opiniões expressas pelos gestores corroboram com os estudos considerados pela revisão de literatura, Adams (2002), Belal e Owen (2007), O'Dwyer (2002, 2003), O'Dwyer, Unerman e Bradley (2005) e Wilmshurst e Frost (2000).

Deve-se ressaltar, entretanto, que o resultado da investigação não pode ser generalizado, por motivos já explicitados. Isso significa que novas investigações podem ser realizadas para verificar a percepção dos gestores de todas as empresas 
do segmento considerado. Mais precisamente, comparando-se os resultados entre as companhias de eletricidade estatais e privadas, objetivando identificar se há diferenças significativas entre as respostas. Outra sugestão de pesquisa é analisar a percepção dos gestores das companhias que negociam na BM\&FBOVESPA e participam do programa de Responsabilidade Social da mesma. Assim, os resultados poderão ser relacionados com o nível de governança corporativa, o desempenho, o tamanho e o volume de evidenciação voluntária de informações socioambientais.

Mesmo com algumas limitações, já declinadas no corpo deste trabalho, entendemos que o presente estudo representa mais um passo de grande significado no processo de compreensão das práticas contábeis que se adotam no contexto das organizações brasileiras e, particularmente, entre aquelas que operam no setor elétrico. Serviu, por exemplo, para comprovar que a decisão de se investir em evidenciações de caráter social e ambiental não é destituída de fundamento. Pelo contrário, está fortemente ancorada no desejo de construir, ampliar ou recuperar legitimidade perante certos agentes que tem potencial para influenciar os destinos da própria organização.

\section{REFERÊNCIAS}

ADAMS, C. A. Internal organisational factors influencing corporate social and ethical reporting: Beyond current theorising. Accounting Auditing \& Accountability Journal. Vol. 15, No. 2, p. 223-250, 2002.

BELAL, A.R; OWEN, D. L. The views of corporate managers on the current state of, and future prospects for, social reporting in Bangladesh: An engagement-based study. AAAJ - Accounting, Auditing \& Accountability Journal, Vol. 20, No. 3, p. 472 $-494,2007$.

BRUNI, A. L. SPSS Aplicado à Pesquisa Acadêmica. São Paulo: Atlas, 2009.

CAMPBELL, J. L. Why Would Corporations Behave in Socially Responsible Ways? An Institutional Theory of Corporate Social Responsibility. Academy of Management Review. Vol. 32, No. 3, p. 946-967, 2007.

CLARKSON, P. M. et al. Revisiting the relation between environmental performance and environmental disclosure: An empirical analysis. AOS Accounting, Organizations and Society, (2007), doi:10.1016/j.aos.2007.05.003. 
DEEGAN, C. The legitimizing effect of social and environmental disclosures - a theorical foundation. AAAJ - Accounting, Auditing \& Accountability Journal, Vol. 15, No. 3, p. 282-311, 2002.

DEEGAN, C.; GORDON, B. A study of the environmental disclosures practices of Australian corporations. Accounting and Business Research. Vol. 26, No. 3, p. 187199, 1996.

DEEGAN, C.; RANKIN, M. Do Australian companies report environmental news objectively? An analysis of environmental disclosure by firms prosecuted successfully by the environmental protection authority. Accounting, Auditing e Accountability Journal. Vol. 9, p. 50 - 67, 1996.

DIAS FILHO, J. M; MACHADO, L. H. B. Abordagens da Pesquisa em Contabilidade. In: IUDÍCIBUS, S. de. ; LOPES, A. B. Teoria avançada da contabilidade. 1 ed. São Paulo: Atlas, 2004.

DIMAGGIO, P. J.; POWELL, W. W. The iron cage revisited: institutional isomorphism and collective rationality in organizational fields. American Sociological Review, Vol. 48, No. 2, p. 147-60, 1983.

FURTADO, J. S. Sustentabilidade Empresarial: Guia e práticas econômicas, ambientais e sociais. Salvador: Neama/ CRA, 2005.

GIL, A. C. Como elaborar projetos de pesquisa. 4. ed. São Paulo: Atlas, 2002.

GRAY, R. The social accounting project and Accounting Organizations and Society: Privileging engagement, imaginings, new accountings and pragmatism over critique? Accounting, Organizations and Society. Vol. 27, p. 687-708, 2002.

IUDÍCIBUS, S. de. Teoria da Contabilidade. 10 ed. São Paulo: Atlas, 2010.

LAKATOS, E. M; MARCONI, M. A. Fundamentos da Metodologia Científica. 5 ed. São Paulo: Atlas, 2003.

MILNE, M.; PATTEN, D. Securing organizational legitimacy: an experimental decision case examining the impact of environmental disclosures. AAAJ Accounting, Auditing \& Accountability Journal, Vol. 15, No. 3, p. 372-405, 2002.

MUSSOI, A.; VAN BELLEN, H. M. Evidenciação ambiental: uma comparação do nível de evidenciação entre os relatórios de empresas brasileiras. RCO - Revista de Contabilidade e Organizações - FEA-RP/USP. Vol. 4, No. 9, p. 55-78, mai-ago 2010. 
NASCIMENTO, A. R. et al. Disclosure Social e Ambiental: análises das pesquisas científicas veiculadas em periódicos de língua inglesa. Revista Contabilidade Vista \& Revista. Universidade Federal de Minas Gerais. Vol. 20, No. 1, p. 15-40, 2009.

O'DONOVAN, G. Environmental disclosures in the annual report: extending the applicability and predictive power of legitimacy theory. AAAJ - Accounting, Auditing \& Accountability Journal, Vol. 15,Non. 3, p. 344-371, 2002.

O'DWYER, B. Conceptions of corporate social responsibility: the nature of managerial capture. AAAJ - Accounting, Auditing \& Accountability Journal, Vol. 16 No. 4, p. 523-57, 2003.

O'DWYER, B. Managerial perceptions of corporate social disclosure: an Irish story. AAAJ - Accounting, Auditing \& Accountability Journal, Vol. 15 No. 3, p. 406-36, 2002.

PATTEN, D. M. Intra-industry environmental disclosures in response to the Alaskan oil spill: a note on legitimacy theory. Accounting, Organizations and Society. Vol. 15, No. 5, p. 471- 475, 1992.

PATTEN, D.; CHO, C. The role of environmental disclosures as tools of legitimacy: a research note. AOS - Accounting, Organizations and Society, Vol. 32, p. 639-647, 2007.

SANTOS, A. R. dos. Metodologia Científica: a construção do conhecimento. 4 ed. Rio de Janeiro: DP\&A Editora, 2001.

SUCHMAN, M. C. Managing Legitimacy: Strategic and Institutional Approaches. The Academy of Management Review. Vol. 20, No. 3, p. 571-610, 1995.

TOLBERT, P. S.; ZUCKER, L. G. A Institucionalização da Teoria Institucional. In: Clegg, S., Hardy, C. \& Nordy, W. Handbook de Estudos Organizacionais. Atlas, p. 196-219, 1999.

VILLIERS, C.; STADEN, C. Can Less Environmental disclosure have a legitimizing effect? Evidence from Africa. AOS - Accounting, Organizations and Society, Vol. 31, p. 763-781, 2006.

WILMSHURT, T.; FROST, G. Corporate environmental reporting a test of legitimacy theory. AAAJ - Accounting, Auditing \& Accountability Journal, Vol. 19, No. 4, p. 564-591, 2000. 